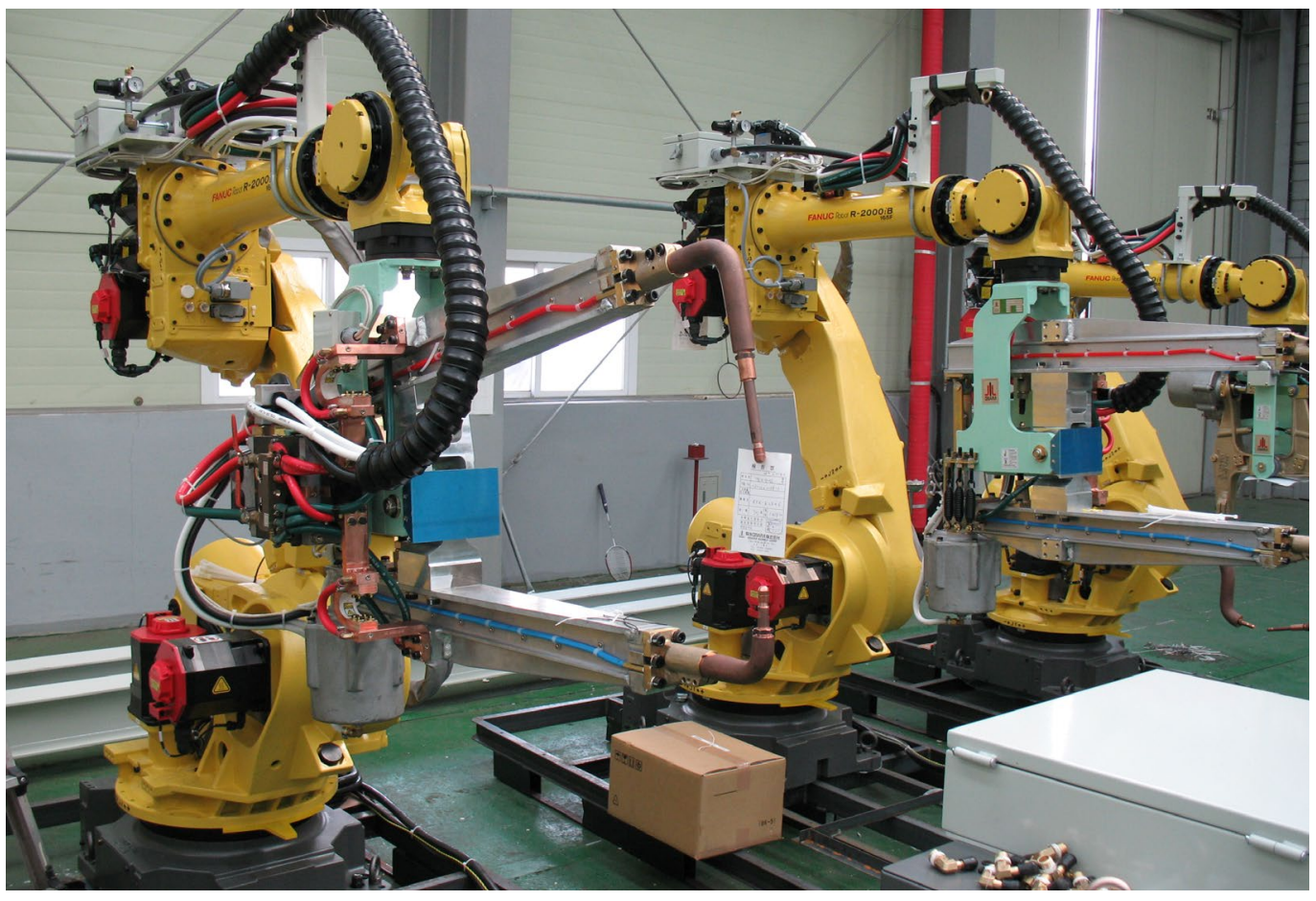

\section{The End of}

\section{Sweatshops?}

\section{Robotisation and the Making of New Skilled Workers in} China

Hui XU

In the past few years, the Chinese labour market has experienced a transition from surplus to shortage of labour, which has led to increased wages for ordinary workers. In such a context, since 2015 the Chinese authorities have pursued a policy of industrial upgrading based on the robotisation of the manufacturing sector. This essay explores the impact of such rapid-employ, large-scale robotisation on labour relations in Chinese factories.
FANUC R-2000iB series robot. PC: Wikimedia Commons.

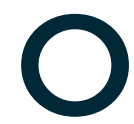
ver the past four decades China has undergone a process of massive industrialisation that has allowed the country to achieve remarkable economic growth. Because of its large manufacturing capacity based on a seemingly unlimited supply of cheap migrant labour in light industries, China has come to be known as the "workshop of the world'. However, since the early 2000 s the country's labour market has experienced a remarkable transition from labour surplus to a 
shortage of labour, which has led to sustained increases in the wages of ordinary workers. In such a context, since 2015 robotisation has become a driving policy for industrial upgrading for manufacturing in China, with the slogan 'replacing human workers with industrial robots' (机器换人) frequently appearing in media reports and official policy documents.

This essay seeks to elucidate the impact of large-scale robotisation on labour relations in Chinese factories. The main argument is that accompanying the application of new production technologies, emerges a new group of skilled workers who possess specific skills related to the operation of industrial robots. Benefitting from the current scarcity of such skills, these workers attain a certain degree of structural power in both the labour market and workplace, which results in wage hikes. The article concludes that, given that industrial upgrading is mainly driven by the Chinese state, the making and developing of new skilled workers is aimed at reorganising labour relations in the largely-robotised manufacturing workshops.

This essay is based on fieldwork conducted by the author between 2011 and 2019 at Foxconn and other factories that are being upgraded in the Pearl River Delta. Group meetings and indepth interviews with people from vocational schools as well as skills training institutes have provided additional material. More specifically, I also spent ten weeks in a commercial robotic skills training institute learning how to install, programme, debug, and maintain industrial robots.

\section{The Macro Dimension of Robotisation}

As the biggest contract electronics manufacturer in the world, Foxconn was notorious for its gruelling production regime that in 2010 resulted in dozens of workers committing suicides. In order to address the instability deriving from workers' grievances, in 2011 Foxconn announced a plan to replace workers with one million robots within three years. In many ways, this ambitious scheme epitomises the tendency of industrial upgrading in Chinese manufacturing industries in recent years, as the current model of economic growth, which relies on labour exploitation, shows its limitations.

Apart from the increasingly vigorous labour activism, structural imbalances in the Chinese economy were a major factor behind such a change of direction, with the Chinese authorities admitting in 2014 that the country was entering a 'new normal' (新 常态) era in which economic growth would be more moderate than in previous decades. In contrast with meteoric growth before, since 2014 the Chinese economy has been under pressure due to the progressive disappearance of the labour dividend. The continuous and rapid growth in the wages of ordinary migrant workers ended up undermining China's comparative advantage, making it difficult for manufacturing enterprises to recruit cheaplypaid workers. Additionally, official figures suggest that manufacturing orders, as well as export volume, are now all declining because of the weakness of European and American markets since the financial crisis in 2008, not to mention the fact that rising labour costs has led to a new round of industrial relocation to cheaper countries in South and Southeast Asia (Chen 2009; Ministry of Commerce 2016). Under such circumstances, the past growth model driven by factor investment is now unsustainable, and Chinese manufacturing industries are forced to upgrade by relying on technological progress and high-quality labour.

Nowadays, the world is witnessing a fourth industrial revolution based on maturing technologies in the fields of artificial intelligence, digital manufacturing, and industrial robots. The decreasing cost and largescale application of these new technologies is making the restructuring of the system of production possible. For instance, employing industrial robots can not only fill in the gap of 
labour scarcity but also improve the functions and quality of products. Unsurprisingly, in this new industrial context, China is confronting fierce international competition from developed countries, including Germany with its Industry 4.0 initiative (Schroeder 2016). Against this background, in 2015 the Chinese authorities released the Made in China 2025 (MiC 2025) plan, which projects a threestep strategy aimed at moving up the value chain by 2025 , and, making China a leading manufacturing power by 2035 (China State Council 2015). Paralleling the German Industry 4.0 initiative, MiC 2025 prioritises innovation in manufacturing, as well as integration between information technology and industries in a top-down fashion.

Guangdong province-one of the most critical manufacturing bases in China, where labour shortages have been quite severe in recent years-plays a central role in this strategy. Local governments in the area have issued multiple policies aimed at promoting industrial upgrade. At the provincial level, in July 2015 the Guangdong government released the Guangdong Province Intelligent Manufacturing Development Plan (2015-25) (广东省智能制造发展规划2015-25). At the city level, the municipal government of Dongguan has recently released three official documents, namely the Practical Opinion on Accelerating the Development of Industrial Robot and Intelligent Industrial Equipment (加快推动工 业机器人智能装备产业发展的实施意见), the Action Plan for Promoting the Replacement of Human Workers with Industrial Robots in Dongguan (2014-16) (推进企业“机器换人” 行动计划), and the Funding Management Rules for Replacing Human Workers with Industrial Robots (“机器换人”专项资金管理 办法). Similarly, in May 2015 the municipal government of Foshan released the Foshan City Scheme for Supporting Enterprises to Adopt Industrial Robots and Intelligent Equipment (2015-17) （佛山市扶持企业推进机器人及智能 装备应用实施方案2015-17).
As a result of these policies, the number of robotic manufacturers and their output in Guangdong province has grown significantly. In 2017, 156 enterprises were producing robots, and the total number of installed industrial robots reached approximately 80,000 units (Guangdong Provincial Government 2018). In Dongguan from September 2014 to January 2017, the municipal government invested 38.6 billion yuan on 2,698 robotic projects ( $\mathrm{Yu}$ 2017). At the same time, in Foshan city the municipal Finance Bureau set aside 160 million yuan to subsidise 368 robotic projects that deployed more than 7,000 industrial robots in enterprises (Foshan News 2018).

\section{Robotisation on the Shopfloor}

But what kind of jobs can be replaced by industrial robots? How does the production process work in factories that mainly use industrial robots? To respond to these questions, it is important to look at the dynamics at the shopfloor level.

In spite of all the media emphasis, Foxconn did not achieve the goal of the One Million Robots plan that it had unveiled in 2011. In 2015, however, the company announced again that it would reach 30 percent automation by 2020 (He 2015). According to media reports, the robotic R\&D and production bases of Foxconn are located in Shenzhen and Jincheng, where Foxconn can produce 10,000 industrial robots per year (He 2015). By 2018 the company was deploying more than 80,000 units of industrial robots in its factories across the country (Foxconn Industrial Internet 2019). Foxconn revealed that through automation and upgrading in one of its workshops in Shenzhen the number of assemblers had declined from 318 to 38 , while the production efficiency had increased by 30 percent with the inventory cycle time contracting by 15 percent (Foxconn Industrial Internet 2019). According to company data, in all Foxconn automated 
factories in 2018 productivity had risen by 18 percent, labour cost had shrunk by 84 percent, and management expenses were 8 percent lower.

Mr Day Chia-Peng, the general manager of the Automation Robotics Division at Foxconn, divides automation in production in three stages: the first stage consists of workstation automation by using industrial robots to do the dirty, dangerous, and dull work which workers are not willing to do or which will jeopardise workers physical and mental health; the second stage is the automation of the assembly line by employing not only industrial robots but also other non-standardised automated equipment; the third stage is the automation of an entire workshop, achieving flexible production in assembling, logistics, testing, and packaging (Zhang 2015).

In general, automation upgrading in workshops is a gradual process. Currently, most enterprises are still in the first stage of workstation automation. Nowadays, in Dongguan, if firms can recoup the costs in one and a half years, they would like to use industrial robots to replace human workers (Sun 2017). However, there is rarely an entire assembly line robotised. Only a small number of firms with substantial capital and technical capability can achieve some of the assembly line automatisation and move toward the automation of the whole workshop. The current situation is that leading enterprises can continuously promote automation of whole workshops, while medium and small-sized firms prefer to gradually introduce industrial robots for assembly lines and workstations.

Replacing human workers with industrial robots means that much of the dirty, dangerous, and dull work will be done robotically. Compared to the Taylorist assembly lines, this is a significant improvement of the labour process, as the daily work in workshops is transformed into robotic programming and communication between automated equipment, installing, debugging, and maintaining industrial robots. As I will show in the next section, this also has an impact on labour relations in China.

\section{Strengthening Workers' Structural and Institutional Power}

Industrial automation has gradually changed the composition of the labour force in workshops, with a dramatic decrease of ordinary assemblers as well as a desperate need for skilled workers, including electrical engineers, mechanical engineers, programming engineers, and debugging engineers. According to estimates by China's Ministry of Industry and Information Technology, by 2020 the Chinese labour market will need approximately 200,000 skilled workers in the field of robotic operation and maintenance, system installing and debugging, and system integration and application (Zhai 2017).

Facing this massive demand, the current supply of skilled workers does not suffice. In 2015, about 260,000 industrial robots had been installed in workshops in China, but the whole country had only 165 graduates studying industrial robot technology in higher vocational schools (China Education Daily 2017). This imbalance was due to two reasons. On the one hand, the low-end industrial structure plus the de-skilling production technologies result in lack of investment in migrant workers' skills. On the other hand, the vocational training system in China is still weak and cannot match market demand. As a result, the quality of education and training is usually low.

In the context of such a structural shortage of skilled workers, in theory mastering core technical skills should strengthen the bargaining power of skilled workers in the labour market. Indeed, this is consistent with what I found through my fieldwork. According to my findings, in the Pearl River Delta a student intern who studies industrial robot technology can expect to be paid an average monthly wage of 3,000-3,500 yuan, and even as high as 5,000 yuan, for their apprenticeship. For those who have finished robotic skills training programmes, the average starting 
salary is 6,648 yuan, a relatively-high level compared to the wages of low-skilled ordinary workers. Some experienced workers skilled in installing and debugging industrial robots can even get paid 1,500-2,000 yuan a day. This kind of wage level alone hints at these workers' rising bargaining power on the labour market.

According to my field observations, robotised workshops are also experiencing a reorientation from the previous hierarchical and disciplinary regime of the assembly line to a more dispersive and cooperative management model. Leading firms like Foxconn usually operate on a large scale and can invest massive resources in automation and informatisation upgrading. Moreover, they have the capacity to set up technical departments to recruit and train skilled workers directly. In contrast, in medium- and small-sized manufacturing factories, robotic system integrators are in charge of building automated assembly lines and are responsible for training skilled workers during the project period, so that when they complete the project and withdraw from the manufacturingenterprises, these trained skilled workers can take over the daily operation and maintenance work. Nevertheless, the workers they train only master basic robotic skills and cannot disentangle complex problems. Once a severe fault occurs, if under warranty, integrator companies will dispatch technical engineers to tackle it, but if the warranty has already expired, the manufacturing companies prefer to buy technical services from a thirdparty company. Sometimes, in order to reduce costs, small-sized workshops outsource the work to the self-employed skilled workers.

My preliminary findings suggest that leading firms differ from medium and small-sized factories in terms of forms of employment, wages, and management style. More specifically, engineers in leading firms are usually treated as managerial personnel in that they enjoy higher wages, more training opportunities, and better job security. In medium and smallsized manufacturing factories where skilled workers are responsible for daily operation and maintenance work, their wages are slightly higher than those of ordinary workers, but they rarely have a chance to learn new skills and climb the corporate ladder, so their turnover rate is relatively high. On the other hand, skilled workers from third-party technical service companies and self-employed experienced engineers have no direct employment relations with these manufacturing enterprises, so they enjoy more control over the work process.

\section{Supply-side Reforms}

In order to increase the supply of skilled workers, not only market mechanisms but also governmental intervention is needed. In January 2019, the Chinese authorities issued the National Vocational Education Reform Implementation Plan (国家职业教育改革实 施方案), which aims at improving the quality of vocational education and cultivating highquality labourers and skilled workers. In addition, in March 2019 Prime Minister Li Keqiang declared in the his annual government work report (China State Council 2019), that the central government would invest 100 billion yuan in training more than 15 million workers, and that migrant workers would be eligible for the first time to enrol in higher vocational schools. The following Vocational Skills Improvement Action Plan (2019-21) ( 职业技能提升行动方案2019-21), published by the State Council in May 2019, further details the goal of subsidising skills training for more than 50 million workers, with the aim of having skilled workers accounting for 25 percent of the entire employed workforce by 2021 . Meanwhile, a system that connects skills training with a professional qualification certificate scheme is also under construction as a basis for professional admittance, assessment, and promotion.

The reform of the skills formation system aims at improving the quality of the available training, but the question of how to encourage workers to learn skills is a completely different matter. Generally speaking, skilled workers are 
concerned with wages and urban citizenship. In this regard, in March 2018 the State Council published the Opinions on Improving the Treatment of Skilled Workers（提高技术工 人待遇的意见) to put in place mechanisms for the distribution and growth of wages and other long-term incentives. More importantly, more and more local governments-including Foshan-have begun to grant skilled workers with urban citizenship, allowing them to enjoy equal access to public services.

In sum, robotisation upgrading in manufacturing is strengthening the marketplace and workplace bargaining power of skilled workers. At the workplace level, skilled workers can now demand higher wages, get more training opportunities, enjoy better job security, and establish more cooperative relations with the management; at the marketplace level, the Chinese government is offering skilled workers urban citizenship in order to boost their ranks. Migrant workers also benefit from these changing dynamics, as they are offered substantial training subsidies to improve their skills.

\section{A Solution for the Sweatshop Problem?}

This essay has offered an outline of the current situation of robotisation in manufacturing in China. In phasing out jobs that are usually repetitive, dirty, dangerous, and monotonous, robotisation has the potential to increase productivity, improve the quality of products, and protect migrant workers' health. In this sense, it offers a solution to ease the problems of the sweatshop.

The upgrading of manufacturing technologies also has implications for labour relations on the shopfloor. In a labour market where skilled labour is scarce, skilled workers have strengthened their structural power, obtaining higher wages and more training opportunities. At the same time, disciplinary managerial tactics that are used to control workers on assembly lines are not suitable for these newly-empowered skilled workers. According to the findings that I presented in this essay, the relations between skilled workers and management in robotised manufacturing enterprises are more cooperative, especially when these skilled workers come from robotic body-maker or system integration companies. In general, it is plausible to suppose that, with the reform of the vocational education system as the Chinese authorities invest more resources in cultivating skilled workers, new skilled workers will play a decisive role in the dynamics of industrial relations in China in the coming years. 
This text is taken from Made in China Journal: Volume 5, Issue 1, 2020, edited by Ivan Franceschini, Nicholas Loubere and Christian Sorace, published 2020 by ANU Press, The Australian National University, Canberra, Australia.

doi.org/10.22459/MIC.05.01.2020.05 